\title{
Research on Coal Price Forecast based on ARIMA and SVM combination Model
}

\author{
*Yin Zheng ${ }^{1, \mathrm{a}}$, Kun Yuan ${ }^{2, \mathrm{~b}}$, Lei Dai ${ }^{3, \mathrm{c}}$ \\ ${ }^{1}$ School of Finance, Anhui University of Finance and Economics, Bengbu Anhui, China; \\ ${ }^{2}$ School of Finance, Anhui University of Finance and Economics, Bengbu Anhui, China. \\ ${ }^{3}$ School of Finance, Anhui University of Finance and Economics, Bengbu Anhui, China;
}

\begin{abstract}
China is the largest producer and consumer of coal in the world. Qinhuangdao Port is not only the largest coal export port in the world, but also an important coal transportation hub in China. The study of the change of coal price in Qinhuangdao Port is of great significance to the study of the change of coal price in the whole country. In this paper, in order to avoid the large prediction error of a single prediction model, an ARIMA-SVM parallel combination model is constructed, and the appropriate weight ratio of ARIMA and SVM model is obtained by calculation, so as to obtain more reliable prediction results. The results show that the international competitiveness of the domestic coal market is insufficient, the coal trading system is incomplete and depends too much on coal resources. For this reason, the government should promote the adjustment of energy structure, improve the mode of transportation, actively improve the coal futures trading system, and realize the upgrading of coal industry.
\end{abstract}

\section{Introduction}

As the most widely distributed and most stored energy in the world, coal has been widely used in various fields. China is the largest producer and consumer of coal in the world, and Qinhuangdao Port is not only the largest coal export port in the world, but also an important coal transportation hub in China. The study of the change of coal price in Qinhuangdao Port is of great significance to the study of the change of coal price in the whole country. Coal is also a commodity, and its price is not only regulated by relevant departments, but also affected by domestic and foreign coal markets. At the same time, climatic conditions and energy consumption patterns will also have a certain impact. Studying the trend of coal price can not only provide decision-making basis for coalrelated enterprises, but also ensure the normal life of residents. Hao Jialong and Ning Yuncai (2007) ${ }^{[1]}$ the highest weekly coal price in Qinhuangdao from 2005 to August 30, 2006 is selected as the research object, and the Box-Jenkins method is used to establish the prediction model of ARIMA (1 prime2), which achieves a good shortterm prediction effect. Zou Shaohui, Zhang Jinsuo $(2010)^{[2]}$ by selecting the highest Monday price data of Datong blended coal in Qinhuangdao from January 1994 to December 2008, this paper makes an empirical study on coal price by using unit root test and Monte-Carlo test. The research shows that under normal circumstances, geometric Brownian motion can better fit the changes of coal prices in China; in some sudden cases, the risk-neutral jump-diffusion model can better fit the changes of coal prices in China. Wang Weixian, Chen Lijun (2012) ${ }^{[3]}$ by establishing the BP neural network model to predict and analyze the stock price, and using genetic algorithm to optimize the model, the prediction progress of the model is improved. By constructing the ARIMA-SVM combination model to forecast the coal price, this paper solves the limitation of the single model prediction, effectively improves the prediction accuracy of the model, and puts forward the relevant policy suggestions according to the forecast results.

\section{Data Sources and Basic Theories}

\subsection{Data Sources}

The data of this paper comes from the China Coal Market Network. In order to deal with the problem, the following hypotheses are put forward: (1) the coal price is Qinhuangdao thermal coal price, and the type of coal price is the closing price of coal; (2) the coal price is a nonstationary time series, which is stabilized by the first-order difference.

\subsection{Basic Theory}

ARIMA model is a time series prediction method proposed by Box and Jenkins in the 1970s. ARIMA(p,d,q) is the differential autoregressive moving average model, where $p$ is the autoregressive term, Q is the number of transferred average terms, $d$ is the difference number, AR is autoregressive and MA is the moving average. [1] The 
autoregressive model describes the relationship between the current value and the historical value. The moving average model is the accumulation of error terms in the autoregressive model. The ARIMA model is obtained by combining the autoregressive model, the moving average model and the difference method.

Average absolute percentage error: $\mathrm{MAPE}=$ $\frac{1}{n} \sum_{i=1}^{n}\left|\frac{y_{i}-\widehat{y_{l}}}{y_{i}}\right| \times 100$

Average absolute percentage error: RMSE $=$ $\sqrt{\frac{1}{n} \sum_{i=1}^{n}\left(y_{i}-\widehat{y}_{l}\right)^{2}}$

The SVM method maps the sample space to a highdimensional or even infinite-dimensional feature space through a non-linear mapping, so that the nonlinear separable problem in the original sample space is transformed into a linearly separable problem in the feature space. The basic steps of parallel model to predict time series:

Set the original sequence as $\left\{x_{t}\right\}$, among them, $\mathrm{t}=1,2,3, \ldots, \mathrm{n}$ and $\mathrm{n}$ denote the number of predicted samples.

The predicted value of the I prediction method at $t$ time is $x_{i t}$, The absolute prediction error of the I test method at t time is $E_{i t}=\left|x_{i}-x_{i t}\right|$, among them, $\mathrm{i}=1,2, \mathrm{t}=1,2, \ldots, \mathrm{n}$

Let $l_{1}$ and $l_{2}$ be the weighted coefficients of prediction model I and II respectively, and $l_{1}+l_{2}=1$. Then $\widehat{x_{i t}}=l_{1} x_{1 t}+l_{2} x_{2 t}$ is $x_{i t}$ Combined forecast value of it, $E_{i t}=x_{i}-\widehat{x_{i t}}=l_{1} E_{1 t}+l_{2} E_{2 t}$ represents the prediction error of the combined prediction model at time $\mathrm{t}, \mathrm{J}=\sum_{t=1}^{n} E_{t}^{2}$ is the sum of the square error of the combined prediction.

\section{Prediction of Coal Price Based on ARIMA-SVM Combination Model}

\subsection{Research Ideas}

A single model is often unable to fully reflect the impact of various factors on the future coal price trend, so the parallel combination model of ARIMA-SVM is used to comprehensively consider the impact of various situations on coal price in the future. Based on the prediction results of ARIMA model, combined with the prediction of SVM model, the weights of the two models are calculated, the appropriate weight ratio of ARIMA model and SVM model is obtained, and the simulation results are given.

\subsection{Research Process}

\subsubsection{Establish SVM Model}

Because the sample set formed by all kinds of influence factors is a nonlinear sample set, the processing steps are as follows: first, select the appropriate kernel function and penalty parameters, construct and solve the convex quadratic programming problem, and calculate the optimal solution. Again, carry on the calculation. Finally, the classification decision function is obtained.

The commonly used kernel function is Gaussian kernel function:

$$
K(x, z)=\exp \left(-\frac{\|x-z\|^{2}}{2 \sigma^{2}}\right)
$$

Because the corresponding SVM is a Gaussian radial basis function classifier, the classification decision function in this case is:

$$
f(x)=\operatorname{sign}\left(\sum_{i=1}^{N} \alpha_{i}^{*} y_{i} \exp \left(-\frac{\|x-z\|^{2}}{2 \sigma^{2}}\right)+b^{*}\right.
$$

\subsubsection{The Result of Simulation Experiment}

The simulation experiment is carried out according to the data calculation of standardized residual diagram, histogram + estimated density diagram, Q-Q diagram and related graph, and the simulation results are shown in figure 1 . 

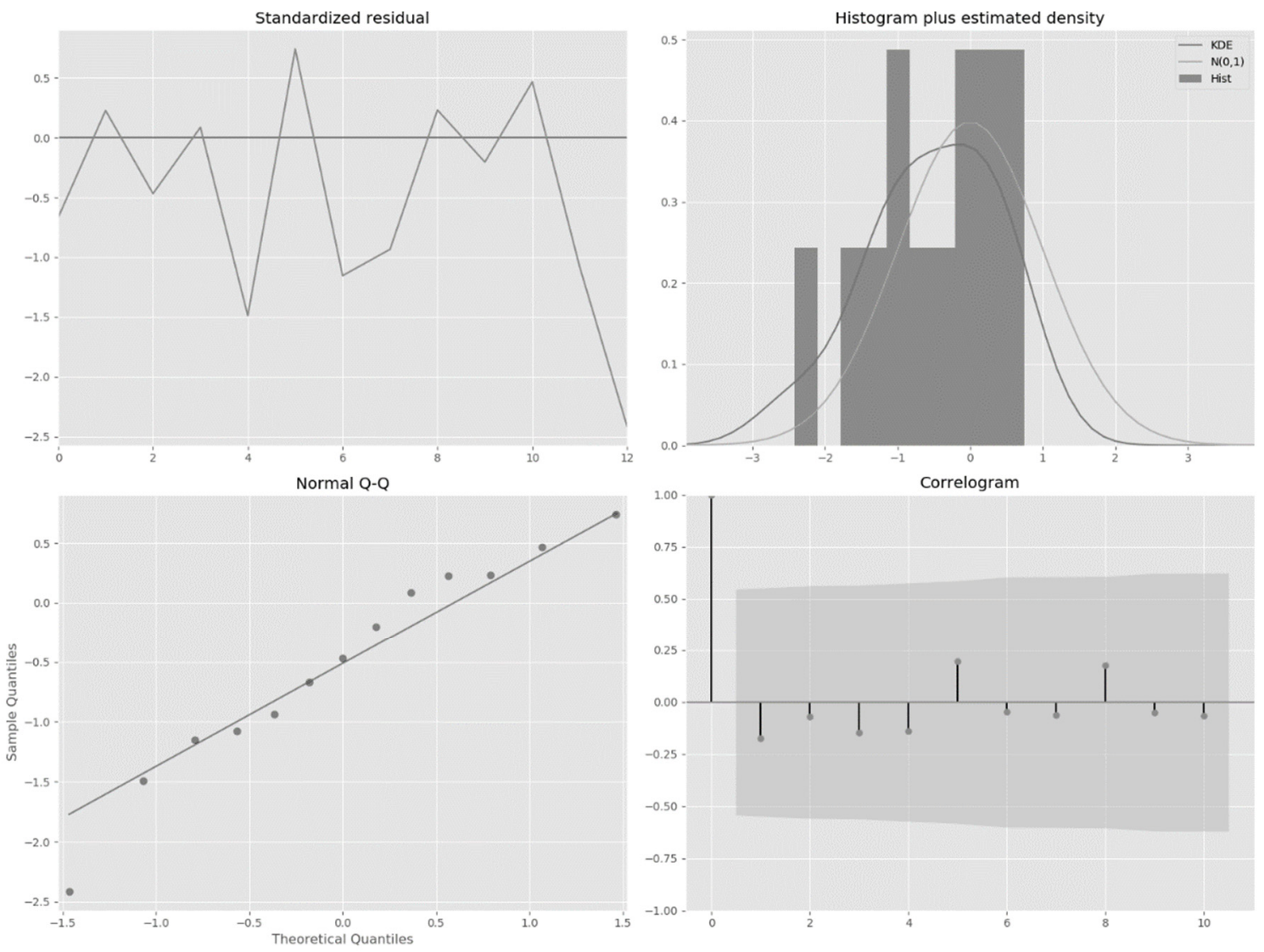

Figure 1 Simulation experiment result diagram

\subsubsection{Weight Calculation of ARIMA-SVM Model}

The forecasting method adopted is parallel combination forecasting. Through the calculation of weights, the appropriate weight ratio of ARIMA and SVM models is obtained as follows:

$$
1_{1}=0.234,1_{2}=0.736
$$

The upper value is substituted into the combination model of ARIMA and SVM, and a new combination forecast result of coal price is obtained, as shown in Table 1.

Table1. Comparison of prediction results

\begin{tabular}{ccccc}
\hline Time & Actual coal price & ARIMA predicted value & SVM predicted value & $\begin{array}{c}\text { Mixed model } \\
\text { predicted value }\end{array}$ \\
\hline January-19 & 590 & 589.7914074 & 589.9002496 & 589.8715211 \\
February-19 & 595.125 & 590.1315466 & 595.0253472 & 593.733649 \\
March-19 & 627 & 598.2740666 & 607.9222222 & 605.3756318 \\
April-19 & 625.625 & 645.1156947 & 607.9222222 & 617.7392842 \\
May-19 & 613.5 & 613.3334072 & 607.9222222 & 609.3504819 \\
June-19 & 597.5 & 613.6050599 & 597.399566 & 601.6769385 \\
July-19 & 600 & 587.3435207 & 599.8996636 & 596.585522 \\
August-19 & 586 & 607.9816698 & 585.9003472 & 591.7286203 \\
September-19 & 586.25 & 572.1375011 & 586.1502496 & 582.451643 \\
October-19 & 580.125 & 595.1498926 & 580.2253472 & 584.1646188 \\
November-19 & 554.5 & 570.6497163 & 557.9222222 & 561.2815912 \\
December-19 & 552.5 & 544.3153586 & 557.9222222 & 554.3307473 \\
January-20 & 561.6 & 557.6615543 & 561.6996636 & 560.6338215 \\
February-20 & 575 & 564.0837376 & 575.099566 & 572.191984 \\
March-20 & 557.5 & 581.8842211 & 557.9222222 & 564.2468919 \\
April-20 & 498 & 542.1223585 & 557.9222222 & 553.7519141 \\
\hline
\end{tabular}




\subsection{Result Analysis}

The MAPE value of coal price forecast based on ARIMASVM combination model is $1.49 \%$, which is lower than that of single ARIMA model and single SVM model, and the fitting effect is better, which avoids the limitation of single model. At the same time, from the simulation experiment, it is further confirmed that the combination model of ARIMA-SVM has a good and reliable prediction effect on coal price.

\section{Relevant policy recommendations based on the above research}

\subsection{Deepen the Supply-side Reform and Promote the Adjustment of China's Energy Structure}

China is a big country of coal production and consumption. As an important strategic resource of our country, coal plays an important role in the economic development of our country. As early as November 2015, President Xi Jinping proposed "supply-side reform", which aims to remove excess capacity and speed up the use of clean energy. According to national data, from 2012 to 2017, state investment in the coal mining and dressing industry has dropped significantly from 537.024 billion yuan to 264.838 billion yuan, and has decreased significantly every year, while domestic coal consumption has not decreased, or even increased slightly. This shows that the supply-side reform of the energy industry has achieved remarkable results, improving the coal industry that was once an extensive development.

\subsection{Optimize the Reform of Transportation System and Reduce the Cost of Coal Price}

At present, the transportation of coal has become a major obstacle to the supply of coal. The transportation cost of coal accounts for $50 \%$ of the total price of coal. Most of the transportation of coal at home and abroad is carried by sea, rail and so on. Railway transport is the main mode of coal transport in China, and more than $60 \%$ of China's coal resources are transported by railway. Speed up the railway construction, separate the government from the enterprises, break the monopoly, encourage non-state-owned capital to enter the railway construction, optimize the railway transport distribution mode, realize the marketization of the railway transport distribution, and increase the distribution rate. it can greatly reduce the transportation cost and rationalize the coal transportation cost. At the same time, buyers and sellers should be allowed to restrict and choose each other and give full play to the role of the competition mechanism.

\subsection{Promote the Reform of Power Generation and Reduce Our Dependence On Coal}

The electric power industry is a mature industry, in essence, there is no problem caused by technology, and the current problem is cost. China is very rich in coal resources, and has quite a lot of good coal quality, so we will choose coal-fired power generation for the sake of economy. The price of thermal power in most provinces is between 0.25 and 0.45 yuan per kilowatt-hour, second only to large-scale hydropower. The approved price of nuclear power is 0.43 yuan per kilowatt-hour, which is obviously higher than that of thermal power in most provinces. Therefore, even today, with the continuous development and application of new energy, thermal power is still the main mode of power supply. only by constantly developing and upgrading new energy and solving the cost problem can we improve the way of power generation that requires the use of coal resources. and then optimize the coal industry. And then reduce the environmental problems caused by coal combustion.

\subsection{Improve the Coal Futures Trading System and Establish Coal Price Index}

In recent years, China's coal export volume is showing a substantial upward trend, but as a big coal country, China does not have an open and complete coal price system, so that other countries can not timely understand the changes of coal prices in China. The establishment of a sound coal futures trading system can promote the relationship between the domestic coal market and the international coal market. At present, China's influence on coal pricing in the international market is not enough. Only by actively connecting with the international market and participating in the international competition, can we improve our influence in the international coal market and make the domestic coal market develop better. In 2013, the China Securities Regulatory Commission approved the application for the listing of thermal coal futures. It is believed that through the listing of more coal futures products, the domestic coal futures trading system can be improved as soon as possible, so that China's coal market can be in line with international standards and improve international competitiveness.

\section{Conclusion}

Through the analysis of the above model, at present, the cost of coal transportation in China is high, so it is necessary to optimize the reform of transportation system. China still relies too much on coal power generation, and it is the key point of the current work to continuously develop and upgrade new energy sources and reduce the dependence on coal. At present, the international competitiveness of the coal market is still insufficient, sound and reasonable coal futures trading system and coal price index, make the domestic coal market in line with international standards, constantly enhance the international influence of the coal market, and achieve the upgrading of the coal industry.

\section{References}

1. J.L. Hao, Y.C. Ning. Research on Coal Price Forecast based on Box-Jenkins method [J]. Prices in China, 
2007,1:10-11,26.

2. S.H. Zou, J.S. Zhang. Empirical study on Coal Price change Model in China [J]. Journal of Coal Industry, 2010, 35(3): 525-528.

3. W.X. Wang, L.J.Chen. Modeling and Simulation of Stock Price Forecast [J]. Computer simulation, 2012, 29(1): 344-347.

4. J.M. Zhu. Analysis and Forecast of influencing factors of Coal Price in China [J]. Chinese coal, 2017,43(11):20-24.

5. W. Zhao. Influencing factors and Forecast Analysis of Power Coal Price [J]. Power generation and air conditioning, 2017,38(2):1-6.

6. K.H. Song, H. Qiao. Post-capacity era Shaanxi thermal coal market analysis and price forecast [J]. Low carbon world, 2016(34):234-235.

7. J.Y. Lv, J.N. Du. Carbon emissions trading price prediction using ARIMA-SVM model [J]. Journal of Xi'an University of Science and Technology, 2020,40(3):542-548.

8. L.D. Chang, Z.J. Liang. Research on Coal cost Forecast based on BP Neural Network [J]. Coal technology, 2019,38(4):180-182. 